\title{
IMPACT OF COMPRESSED AIR PRESSURE ON GEOMETRIC STRUCTURE OF AISI 1045 STEEL SURFACE AFTER TURNING WITH THE USE OF MQCL METHOD
}

\author{
Radosław Wojciech Maruda ${ }^{1}$ \\ 1 Faculty of Mechanical Engineering, University of Zielona Gora, 4 Prof. Z. Szafrana Street, 65-516 Zielona Gora, \\ Poland, e-mail: r.maruda@ibem.uz.zgora.pl
}

Received: 2016.04.15 Accepted: 2016.05.25 Published: 2016.06.01

\begin{abstract}
MQL (Minimum Quantity Lubrication) and MQCL (Minimum Quantity Cooling Lubrication) methods become alternative solutions for dry machining and deluge cooling conditions. Due to a growing interest in MQCL method, this article discusses the impact of compressed air pressure, which is one of the basic parameters of generating emulsion mist used in MQCL method, on the geometric structure of the surface after turning AISI 1045 carbon steel. This paper presents the results of measurements of machined surface roughness parameters $\mathrm{Ra}, \mathrm{Rz}, \mathrm{RSm}$ as well as roughness profiles and Abbot-Firestone curves. It was found that the increase in the compressed air pressure from 1 to $7 \mathrm{MPa}$ causes an increase in the roughness of the machined surface (the lowest values were obtained at a pressure of $1 \mathrm{MPa}$ ). An increase of emulsion mass flow rate also causes an increase in the value of selected parameters of roughness of the machined surface.
\end{abstract}

Keywords: compressed air pressure, emulsion flow, geometric structure, MQCL, near dry cutting.

\section{INTRODUCTION}

Sustainable and economic manufacturing has become a very important process in the automotive and aviation industries $[9,24]$. Despite numerous advantages of cooling lubricants in machining, there are many concerns as to the environmental and economic problems related to their use. Thus, in recent years, many scientists have conducted research associated with a reduction in the use of cooling lubricants or their complete elimination [7, 11, 17, 21].

In the case when completely dry machining is impossible, lubricating systems based on MQL (minimum quantity lubrication) and MQCL (minimum quantity cooling lubrication) methods are good alternatives $[14,20]$. For cooling the cutting zone using these methods, a small amount of cooling lubricants is used $(5-100 \mathrm{ml} / \mathrm{h}$, i.e. approx. 1000 times less than when using deluge cooling) $[14,18]$. Therefore, the consumption of oil and emulsion as well as costs related to their use are significantly reduced. When applying MQL and MQCL methods, the chips, the material to undergo the process of machining and the tools are practically dry, and the costs related to the recycling of coolants are reduced. A small amount of cooling lubricants is sufficient to decrease the friction in machining by reducing the tendency of adhesion in materials with such characteristics [16]. In MQCL method, emulsion mist is supplied to the cutting zone in a form of emulsion spray and compressed air.

Eco-cooling methods have been applied in a number of machining operations, including grinding [5, 6], milling [8], drilling [2] as well as turning $[4,10,13,14]$. It was found that compared to 
dry machining, MQCL and MQL methods reduce the roughness of the machined surface $[4,13]$, the wear of the cutting blade $[1,3,4]$ and the temperature in the cutting zone [3] as well as have a positive effect on the chip shape [14].

Research on the conditions of oil mist generation (MQL) and emulsion mist generation (MQCL) shows that the most significant factors affecting the conditions of generating oil or emulsion mist, and, consequently, its effective use, include the setting of the nozzle (angle and distance) [12, 20, 22], emulsion mass flow rate [22], air pressure and volumetric air flow rate $[12,15$, 19]. Shiva Sai et al. [19] demonstrated that compressed air pressure in MQL method affects the diameter of droplets supplied to the cutting zone. It was also proven that an increase in air pressure causes an increase in the wettability of the cutting zone. During their research, Park et al. [15] observed that as compressed air pressure increases, the number of droplets falling on the contact surface of the blade with the machined material is increased as well and their diameter is reduced.

The aim of this article is to analyze the impact of compressed air pressure as one of the basic parameters of generating emulsion mist used in MQCL method, on the geometric structure of the surface. The knowledge of air pressure parameter is vital for the application of MQCL method in machining processes on an industrial scale.

\section{MATERIALS AND METHODS}

The study was conducted on a lathe with SDBM2020M12 holder and SNUN104008 plate made of P25 cemented carbide coated with TiN (coating thickness $4 \mu \mathrm{m}$, applied using CVD method). The material to undergo the process of machining was AISI 1045 carbon steel (C45 steel according to EN 10083-2: 2006).

A concentrated emulsion WEDOLIT K910 served as the active medium for the emulsion mist. This is a semi-synthetic, water-miscible product based on boric acid $\mathrm{H} 3 \mathrm{BO} 3$ and amines which contains a small amount of mineral oil and polar lubricant additives. The active medium was prepared using type ES21H electromagnetic stirrer to give a $5 \%$ concentrate in water solution.
The apparatus generating emulsion mist is presented in Figure 1. The aerosol in GAV1500 is created in a special chamber, where the emulsion is sucked due to negative pressure. Then, compressed air ensures transportation of the finished aerosol to a discharge nozzle with a diameter of $0.9 \mathrm{~mm}$.

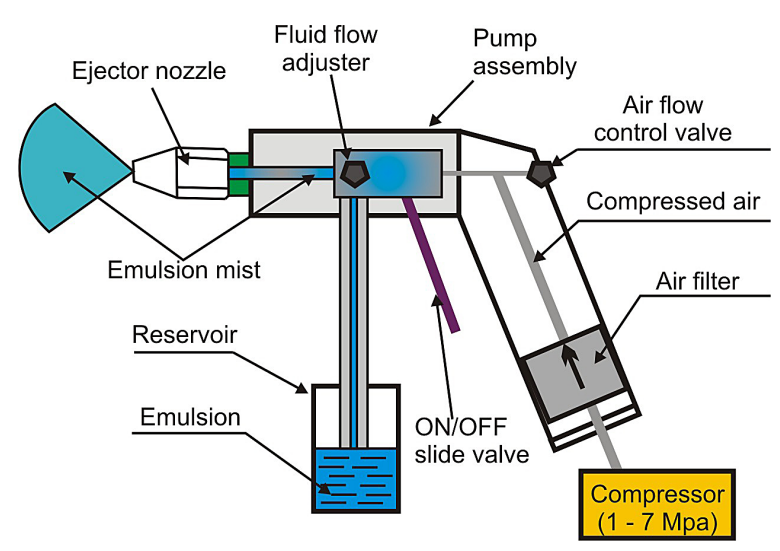

Fig. 1. GAV1500 device that generates emulsion mist

During the turning process, constant machining parameters were applied: feed rate $\mathrm{f}=0.15$ $\mathrm{mm} / \mathrm{rev}$; cutting speed $\mathrm{v}_{\mathrm{c}}=300 \mathrm{~m} / \mathrm{min}$ and depth of cutting $\mathrm{a}_{\mathrm{p}}=0.5 \mathrm{~mm}$, as well as variable parameters of emulsion mist generation:

- mass flow of emulsion $\mathrm{E}=1.5 \div 3.2 \mathrm{~g} / \mathrm{min}$;

- compressed air pressure $\mathrm{P}=1 \div 7 \mathrm{MPa}$;

- distance of the nozzle from the cutting zone $1=0.3 \mathrm{~m} \mathrm{[12]}$.

The roughness measurement was made on TR-200 device in compliance with ISO 4287:1998. The following values were measured: the arithmetic mean value of the profile ordinates $\mathrm{Ra}$, the maximum height of the profile $\mathrm{Rz}$ as well as the root mean square value of the profile ordinates Rq.

\section{RESULTS AND DISCUSSION}

The charts showing changes in the selected roughness parameters of the machined surface of AISI 1045 carbon steel elements after turning, according to variable compressed air pressure $\mathrm{P}$ and emulsion mass flow rate $\mathrm{E}$ are presented in Figure 2.

When analyzing the studied roughness parameters, it was found that an increase in compressed air pressure and emulsion mass flow rate 
causes an increase of the roughness parameters. At relatively high emulsion flow rates $(E=3.2$ $\mathrm{g} / \mathrm{min}$ ) (Figure 2a), an increase in air pressure by $1 \mathrm{MPa}$ caused the Ra parameter to increase by $6 \%$, and after exceeding the value of $2 \mathrm{MPa}$, the change is within the scope of $\pm 2 \%$. The greatest percentage differences for Ra and Rz parameters were observed at variable emulsion mass flow rates and low compressed air pressure values $(<2.5 \mathrm{MPa})$. This increase in the selected parameters with the increase of compressed air pressure might be caused by the fact that droplets are ejected from the nozzle at a higher speed, which may lead to turbulence and change in the direction of movement of these droplets, thus reducing their quantity supplied to the cutting zone.

a)

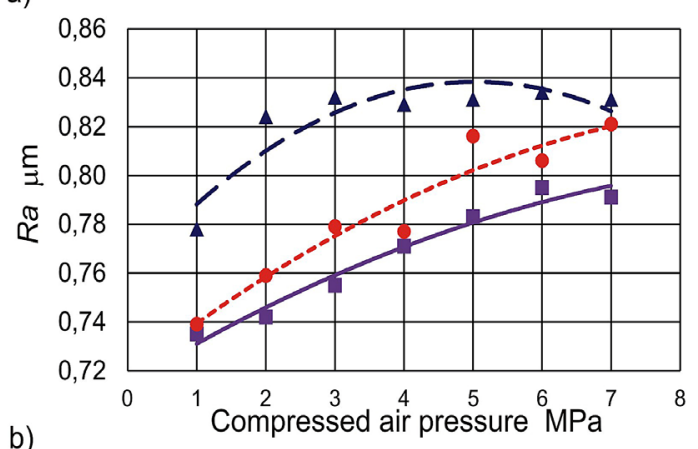

b)

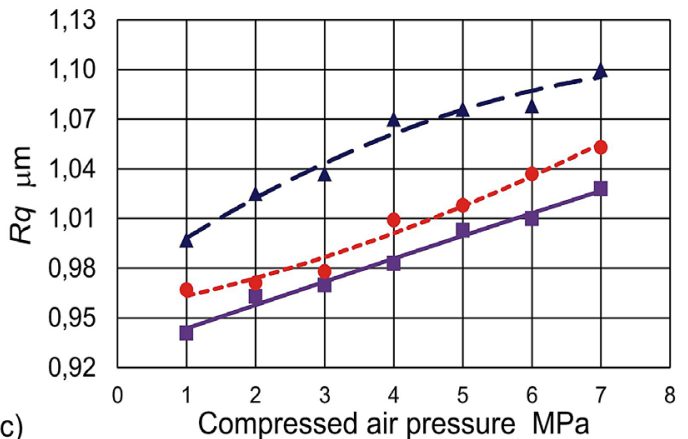

c)

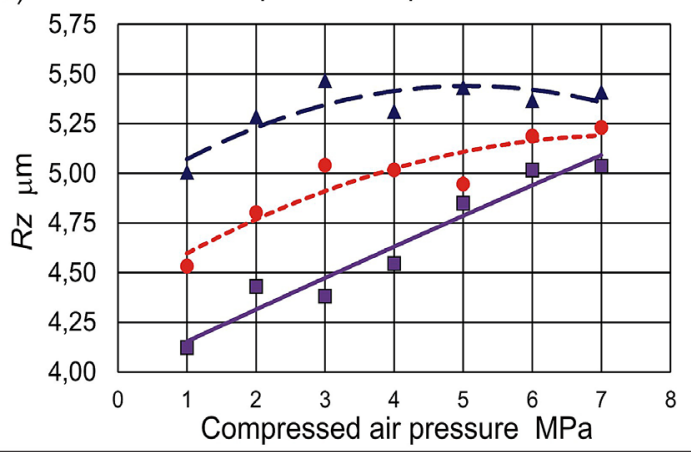

$\rightarrow-E=1.5 \mathrm{~g} / \mathrm{min}---E=2.5 \mathrm{~g} / \mathrm{min}-\mathbf{t}-E=3.2 \mathrm{~g} / \mathrm{min}$

Fig. 2. Impact of compressed air pressure on the roughness of machined AISI 1045 carbon steel surface after turning at various emulsion mass flow rates:

a) Ra parameter; b) Rq parameter; c) Rz parameter
Figure 3 shows typical roughness profiles and Figure 4 - Abbot-Firestone curves for AISI 1045 steel after turning with the use of MQCL method for $\mathrm{E}=2.5 \mathrm{~g} / \mathrm{min}$ and three different compressed air pressure values.

As can be seen in Fig. 3, the correct selection of conditions for the generation of emulsion mist with the use of MQCL method (compressed air pressure) affects the shape of the roughness profiles of machined surfaces. A significant reduction of the height of unevenness (Fig. 3a) can significantly affect the operating properties of this surface, including the friction coefficient and wear rate [23].

a) 20

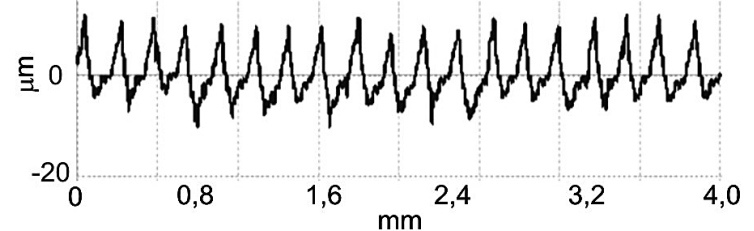

b)
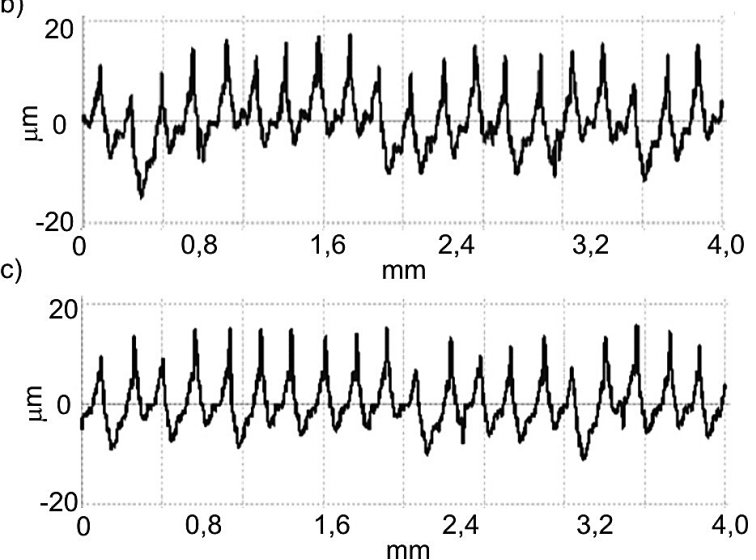

Fig. 3. Roughness profiles of 1045 carbon steel surface after turning with the use of MQCL method with different compressed air pressure values for $\mathrm{v}_{\mathrm{c}}=300$ $\mathrm{m} / \mathrm{min}, \mathrm{f}=0.15 \mathrm{~mm} / \mathrm{rev}, \mathrm{E}=2.5 \mathrm{~g} / \mathrm{min}$ : a) $\mathrm{P}=1 \mathrm{MPa}$;

b) $\mathrm{P}=4 \mathrm{MPa}$; ) $\mathrm{P}=7 \mathrm{MPa}$

From the Abbot-Firestone curves (Fig. 4), it is visible that for $1 \mathrm{MPa}$ of compressed air pressure, the shape of the curve is most S-like (first, it falls steeply, then it becomes more flat, and the end-section falls steeply again). The shape of this curve (Fig. 4a) proves that the upper part of the surface will be worn quickly after the initiation of friction between two surfaces. The long straight section after the run-in period shows good load bearing capacity of the surface as well as good operating resistance under high stress [23]. 
a)

C (\% Ry)

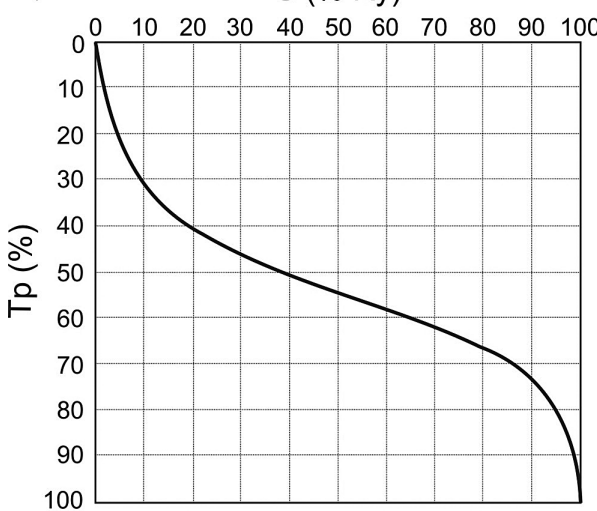

b)

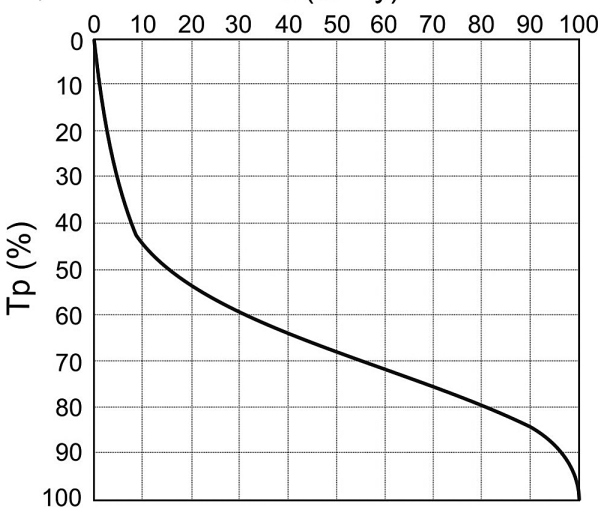

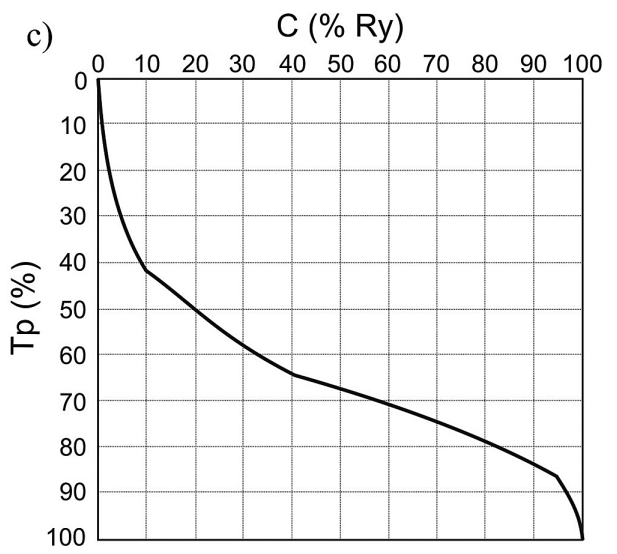

Fig. 4. Abbot-Firestone curves for 1045 carbon steel after turning with the use of MQCL method with different compressed air pressure values for $\mathrm{vc}=300 \mathrm{~m} / \mathrm{min}, \mathrm{f}=0.15 \mathrm{~mm} / \mathrm{rev}, \mathrm{E}=2.5 \mathrm{~g} / \mathrm{min}$ : a) $\mathrm{P}=1 \mathrm{MPa}$; ) $\mathrm{P}=4 \mathrm{MPa}$; c) $\mathrm{P}=7 \mathrm{MPa}$

\section{CONCLUSIONS}

The parameters of generating emulsion mist greatly affect the geometric structure of the surface. The lowest values of selected roughness parameters were obtained for low compressed air pressure $(\mathrm{P}=1 \mathrm{MPa})$ and emulsion mass flow rate $(\mathrm{E}=1.5 \mathrm{~g} / \mathrm{min})$. An increase in pressure by $1 \mathrm{MPa}$ in GAV1500 device causes an increase in the values of selected roughness parameters from $2 \%$ to $20 \%$. The chosen roughness profiles and Abbot-Firestone curves demonstrate that the best efficiency of generating emulsion mist with the use of MQCL method in terms of quality of the machined surface can be obtained for low emulsion flow and low pressure of the compressed air.

\section{REFERENCES}

1. Chinchanikar S., Choudhury S.K. Hard turning using HiPIMS-coated carbide tools: Wear behavior under dry and minimum quantity lubrication
(MQL). Measurement, 55, 2014, 536-548.

2. Davim J.P., Sreejith P.S., Gomes R., Peixoto C. Experimental studies on drilling of aluminum (AA1050) under dry, minimum quantity of lubricant, and flood-lubricated conditions. Proceedings of the Institution of Mechanical Engineers, Part B: Journal of Engineering Manufacture, 220 (10), 2006, 1605-1611.

3. Debnath S., Reddy M.M., Yi Q.S. Environmental friendly cutting fluids and cooling techniques in machining: a review. Journal of Cleaner Production, 83, 2014, 33-47.

4. Dhar N.R., Kamruzzaman M., Ahmed M. Effect of minimum quantity lubrication (MQL) on tool wear and surface roughness in turning AISI-4340 steel. Journal of Materials Processing Technology, 172 (2), 2006, 299-304.

5. Hadad M.J., Tawakoli T., Sadeghi M.H., Sadeghi B. Temperature and energy partition in minimum quantity lubrication-MQL grinding process. International Journal of Machine Tools and Manufacture, 54-55, 2012, 10-17.

6. Hafenbraedl D., Malkin S. Technology environmentally correct for intern cylindrical grinding. 
Machines and Metals Magazine, 426, 2001, 40-55.

7. Jozwik J., Mika D. Diagnostics of workpiece surface condition based on cutting tool vibrations during machining. Advances in Science and Technology-Research Journal, 9 (26), 2015, 57-65.

8. Kedare S.B., Borse D.R., Shahane P.T. Effect of minimum quantity lubrication (MQL) on surface roughness of mild steel of $15 \mathrm{HRC}$ on universal milling machine. Procedia Materials Science, 6, 2014, 150-153.

9. Krolczyk J., Krolczyk G., Legutko S., Napiorkowski J., Hloch S., Foltys J., Tama E. Material flow optimization - a case study in automotive industry. Tehnicki Vjesnik - Technical Gazette, 22 (6), 2015 , 1447-1456.

10. Leppert T. Effect of cooling and lubrication conditions on surface topography and turning process of C45 steel. International Journal of Machine Tools and Manufacture, 51 (2), 2011, 120-126.

11. Marinescu I.D., Rowe W.B., Dimitrov B., Inasaki I. in: Tribology of Abrasive Machining Processes. William Andrew, USA, 2004.

12. Maruda R.W., Feldshtein E., Legutko S, Królczyk G.M. Research on emulsion mist generation in the conditions of Minimum Quantity Cooling Lubrication (MQCL). Tehnicki Vjesnik - Technical Gazette, 22 (5), 2015, 1213-1218.

13. Maruda R.W., Legutko S., Krolczyk G.M., Hloch $\mathrm{S}$. Michalski M. An influence of active additives on the formation of selected indicators of the condition of the X10CrNi18-8 stainless steel surface layer in MQCL conditions. International Journal of Surface Science and Engineering. 9 (5), 2015, 452-465.

14. Maruda R.W., Legutko S., Krolczyk G.M., Raos P. Influence of cooling conditions on the machining process under MQCL and MQL conditions. Tehnicki Vjesnik - Technical Gazette. 22 (4), 2015 , 965-970.

15. Park K.H., Olortegui-Yume J., Yoon M.C., Kwon P. A study on droplets and their distribution for minimum quantity lubrication (MQL). International Journal of Machine Tools and Manufacture, 50 (9), 2010, 824v833.

16. Pusavec F., Krajnik P., Kopac J. Transitioning to sustainable production - part I: application on machining technologies. Journal of Cleaner Production, 18 (2), 2010, 174-184.

17. Pusavec F., Kramar D., Krajnik P., Kopac J. Transitioning to sustainable production - part II: evaluation of sustainable machining technologies. Journal of Cleaner Production. 18 (12), 2010, 1211-1221.

18. Sadeghi M.H., Hadad M.J., Tawakoli T., Vesali A., Emami M. An investigation on surface grinding of AISI 4140 hardened steel using minimum quantity lubrication-MQL technique. International Journal of Material Forming, 3 (4), 2010, 241-251.

19. Shiva Sai S., Manoj Kumar K., Ghosh A. Assessment of spray quality from an external mix nozzle and its impact on SQL grinding performance. International Journal of Machine Tools and Manufacture, 89, 2015, 132-141.

20. Silva L.R., Bianchi E.C., Catai R.E., Fusse R.Y., Franca T.V., Aguiar P.R. Study on the behavior of the minimum quantity lubricant - MQL technique under different lubrication and cooling conditions when grinding ABNT 4340 steel. Journal of the Brazilian Society of Mechanical Sciences and Engineering, 27 (2), 2005, 192-199.

21. Tawakoli T., Azarhoushang B. Influence of ultrasonic vibrations on dry grinding of soft steel. International Journal of Machine Tools and Manufacture, 48 (14), 2008, 1585-1591.

22. Tawakoli T., Hadad M.J., Sadeghi M.H. Influence of oil mist parameters on minimum quantity lubrication-MQL grinding process. International Journal of Machine Tools and Manufacture. 50 (6), 2010, 521-531.

23. Tomasik J., Haratym R. Attempt to apply the parameters in the Abbot-Firestone curve to the description of the microgeometry of precision casting surfaces. Archiwum Odlewnictwa, 4, 2004, 532-537.

24. Wojciechowski S., Chwalczuk T., Twardowski P., Krolczyk G.M. Modeling of cutter displacements during ball end milling of inclined surfaces. Archives of Civil and Mechanical Engineering, 15 (4), 2015, 798-805. 